\title{
TRADISI SUROAN SEBAGAI TAPAK TILAS WALISONGO (STUDI DI DESA JATIREJO KECAMATAN SURUH KABUPATEN SEMARANG)
}

\author{
Damar Safera \\ Institut Agama Islam Negeri Salatiga \\ damarsafera@gmail.com \\ Muhammad Chairul Huda \\ Institut Agama Islam Negeri Salatiga \\ Mahasiswa Program Doktor Ilmu Hukum UNDIP Semarang \\ choirulhuda@iainsalatiga.ac.id
}

\begin{abstract}
Tradition is a pattern of behavior that has deep roots in a society or can be interpreted as a habit that has long been carried out by a certain community in an area, which means carrying out the tradition means also carrying out the process of socialization between generations. Eachs region has a different culture. One of the traditions that is still carried out by the people in Jatirejo Village is the Suroan tradition or commonly called 1 Mubarram. The Suroan tradition is a traditional Javanese ceremony in welcoming the Javanese new year which is a cultural assimilation of Javanese culture and Islamic culture carried out by Sultan Agung. People in the village of Jatirejo themselves celebrate it with various forms of activities carried out each year. Suroan tradition which aims to express gratitude to Allah SWT, asking for fortune to be given blessings and gratitude for the harvest and most importantly, so that villagers avoid all kinds of dangers and diseases that afflict or reject. The implementation of the Suroan tradition in the village of Jatirejo, begins with a deliberation between residents and local village officials, then the main event of the Suroan and closing traditions. As for the problem formulation in this study is "how are the economic and religious motives implications in the implementation of the Suroan tradition in the community of Jatirejo Village, Surub District, Kab. Semarang".
\end{abstract}

Keywords: Culture, Tradition, Walisongo

\section{Abstrak}

Tradisi merupakan suatu pola tingkah laku yang telah berakar mendalam dalam suatu masyarakat atau bisa diartikan sebagai kebiasaan yang telah lama dilakukan oleh suatu masyarakat tertentu dalam suatu daerah, yang berarti melaksanakan tradisi berarti juga melaksanakan proses sosialisasi antar generasi. Setiap daerah mempunyai kebudayaan yang berbeda-beda. Salah satu tradisi yang masih dilaksanakan oleh masyarakat di Desa Jatirejo adalah tradisi Suroan atau lebih sering dikenal dengan 1 Muharram. Tradisi Suroan merupakan upacara tradisional Jawa dalam menyambut tahun baru Jawa yang merupakan asimilasi budaya dari budaya Jawa dan budaya Islam yang dilakukanoleh Sultan Agung. Masyarakatdi desa Jatirejo sendiri merayakanya dengan berbagai bentuk kegiatan yang dilaksanakan setiap tahunnya. Tradisi Suroan yang bertujuan untuk mengungkapkan rasa syukur kepada Allah SWT, meminta rejeki agar diberikan keberkahan serta rasa syukur warga atas hasil panen dan yang paling penting yaitu agar warga desa terhindar dari segala bahaya dan penyakit yang menimpa atau tolak-balak. Pelaksanaan tradisi Suroan di Desa Jatirejo, Diawali dengan melakukan musyawarah antar warga dan perangkat desa setempat, kemudian pelaksanaan acara inti dari tradisi Suroan dan penutup. Adapun yang menjadi rumusan 
masalah dalam penelitian ini adalah "bagaimanakah implikasi motif ekonomi dan keagamaan dalam pelaksanaan tradisi Suroan pada masyarakat Desa Jatirejo Kecamatan Suruh, Kab. Semarang". Metode yang digunakan adalah metode deskriptif. Teknik pengumpulan yang digunakan adalah teknik observasi partisipasi, dokumentasi dan wawancara. Sedangkan teknik analisis data yang digunakan adalah teknik analisis data kualitatif. Hasil dari analisis data dalam artikel ini menunjukkan bahwa tatacara pelaksanaan tradisi Suroan di Desa Jatirejo beraneka ragam, keberagaman ini akibat dari implikasi motif ekonomi dan keagamaan yang mempengaruhi pelaksanaannya. Walaupun ada berbedaan akan tetapi tidak menghilangkan tujuan dan makna dari pelaksanaan tradisi Suroan yang rutin dilakukan oleh masyarakat Jawa di Desa Jatirejo, Kecamatan Suruh, Kabupaten Semarang.

Kata kunci: Budaya, Tradisi, Walisongo

\section{PENDAHULUAN}

Indonesia merupakan negara yang besar dan memiliki keanekaragaman suku, agama, ras dan kebudayaan. ${ }^{1}$ Dari ratusan suku yang terdapat di Indonesia, salah satunya adalah suku Jawa ${ }^{2}$. Suku Jawa merupakan suku terbesar di Indonesia. ${ }^{3}$ Dalam perkembangan kebudayaan masyarakat Jawa terdapat akulturasi dengan berbagai bentuk kebudayaan lain yang masuk dan mempengaruhi tradisi masyarakat Jawa. ${ }^{4}$ Oleh karena itu corak dan bentuknya diwarnai oleh berbagai bentuk unsur budaya dan agama yang bermacam-macam. ${ }^{5}$ Masyarakat Jawa memiliki aktualisasi kebudayaan yang beragam, hal ini dikarenakan motif agama, sosial, hukum, ekonomi dan faktorfaktor lain yang mempengaruhi pelaksanaannya ${ }^{6}$.

Masing masing suku dalam sebuah daerah, memiliki berbagai macam tadisi yang berbeda antara suatu tradisi dengan tradisi yang lainnya. Adapun ciri khas yang dimilki masing-masing suku ataupun daerah tersebut di satu pihak ada yang masih mempertahankan tradisi disuatu masyarakat itu dan tidak mengalami perubahan sama sekali, dipihak lain ada yang mengalami perubahan bahkan ada yang tidak melestarikan sebagai tradisi di masyarakat tersebut. ${ }^{7}$ Dalam tradisi Suku Jawa, salah satu tradisi yang masih dipertahankan yaitu Ritual Bulan Suro (Asy-Syuro) yang lebih akrab dikenal dengan tradisi Suroan, tradisi ini dilakukan masyarakat untuk menghindari kesialan, bencana, musibah. Tradisi ini dilakukan dengan disertai berbagai macam

\footnotetext{
${ }^{1}$ Nordin, N. H. (2018). Ritual Bajamu Pada Etnis Melayu di Desa Sei Sanggul Kecamatan Panai Hilir Kabupaten Labuhan Batu (Doctoral dissertation, UNIMED).

2_Siburian, A. L. M., \& Malau, W. (2018). Tradisi Ritual Bulan Suro pada Masyarakat Jawa di Desa Sambirejo Timur Percut Sei Tuan. Gondang: Jurnal Seni dan Budaya, 2(1), 28-35.

3 Pitoyo, A. J., \& Triwahyudi, H. (2017). Dinamika Perkembangan Etnis di Indonesia dalam Konteks Persatuan Negara. Populasi, 25(1), 64-81.

${ }^{4}$ Azis, D. K. (2013). Akulturasi Islam dan Budaya Jawa. Sekolah Tinggi Agama Islam Negeri Kudus.

${ }^{5}$ Hartono, H., \& Firdaningsih, F. (2019). Akulturasi Islam dengan Budaya Jawa dalam Ritual Sedekah Laut di Pantai Pedalen Kabupaten Kebumen. IBD A: Jurnal Kajian Islam dan Budaya, 17(2), 364-380.

6 Landriany, E. (2019). Tindakan Sosial Berorientasi Nilai dalam Pelestarian Lingkungan (Studi Etnografi Komunitas Peduli Lingkungan Di Dusun Lemah Putib Desa Sumber Brantas Kecamatan Bumiaji Kota Batu) (Doctoral dissertation, University of Muhammadiyah Malang).

${ }^{7}$ Muttaqi, U. K. (2016). Rancang bangun konverter kalender Hijriah ke kalender Masehi untuk memperkirakan hari besar umat Islam menggunakan Matlab (Doctoral dissertation, UIN Walisongo).
} 
kegiatan lain, seperti halnya haul (pengajian), brokohan (acara syukuran atau slametan), malam tirakatan, pawai ta'aruf (karnaval) dan sebagainya.

Di Desa Jatirejo, masyarakat masih menjaga dan melestarikan kegitan Suroan tersebut. Sehingga masyarakat yang ada di Desa Jatirejo Kecamatan Suruh, Kabupaten Semarang masih memperingati Tradisi Suroan tersebut setiap tahunnya. Bagi umat Islam, tanggal 1 Muharram (dalam kalender Hijriyah) atau lebih dikenal dengan 1 Suro merupakan bulan yang suci, karena dianggap sebagai bulan yang baik untuk memperbaiki diri dan ungkapan rasa syukur kepada Allah SWT atas kenikmatan dan keberkahan hidup. Dalam sistem kalender Hijriah tanggal 1 Muharram merupakan awal tahun baru Islam. Selain menggunakan sistem kalender Hijriah, masyarakat Jawa-Islam juga menggunakan sistem kalender Jawa yang dibawa sejak masa pemerintahan Sultan Agung (1613-1645M). ${ }^{8}$

Pandangan masyarakat Jawa terhadap bulan Suro sering dianggap sebagai bulan baik, namun juga sering disebut sebagai bulan yang penuh mara bahaya. ${ }^{9}$ Bagi pemilik keris biasanya keris tersebut harus dicuci atau dimandikan (dicuci) dengan air kembang (bunga) lengkap dengan kemenyan, dupa serta ubo rampe yang lain saat malam satu Suro. ${ }^{10}$ Desa Jatirejo dipilih dalam penelitian ini karena di desa tersebut melaksanakan tradisi Suroan setiap tahun dan tempat yang di gunakan memiliki keunikan tersendiri, yakni tempat yang dipercaya masyarakat sebagai “petilasan” Walisongo atau sering disebut sebagai Balai Panjang.

Berdasarkan uraian diatas dapat rumusan masalah dalam penelitian ini sebagai berikut; pertama, bagaimana tata cara pelaksanaan Tradisi Suroan di Desa Jatirejo Kabupaten Semarang; kedua, bagaimana makna dan nilai yang terkandung dari adanya pelaksanaan Tradisi Suroan; ketiga, bagaimana implikasi motif ekonomi dan keagamaan dalam pelaksanaan tradisi Suroan pada masyarakat Desa Jatirejo, Kecamatan Suruh, Kabupaten Semarang. Tujuan penelitian ini adalah; pertama, untuk mengetahui tata cara pelaksanaan Tradisi Suroan di Desa Jatirejo; kedua, untuk mengetahui makna dan nilai yang terkandung dari adanya pelaksanaan tradisi Suroan; ketiga, untuk mengetahui implikasi ekonomi dan keagamaan dalam pelaksanaan tradisi Suroan pada masyarakat Desa Jatirejo Kabupaten Semarang.

Metode yang digunakan adalah metode deskriptif kualitatif dengan teknik pengumpulan data yang digunakan adalah teknik observasi partisipasi, dokumentasi dan wawancara. Informan dari penelitian ini adalah Fahrurrazi Alwi (42 tahun) yang merupakan tokoh agama Desa Jatirejo, Anwar Hidayat (45 tahun) yang merupakan Kepala Dusun Desa Jatirejo, Rizal (36 tahun)

${ }^{8}$ Masruhan, M. (2017). Islamic Effect on Calender of Javanese Community. Al-Mizan, 13(1), 53-68.

9 Sholikhin, M. (2010). Misteri bulan Suro: perspektif Islam Jawa. Penerbit Narasi.

${ }^{10}$ Japarudin, J. (2017). Tradisi Bulan Muharam di Indonesia. Tsaqofah dan Tarikh: Jurnal Kebudayaan dan Sejarah Islam, 2(2), 167-180. 
sebagai salah satu ketua rukun tetangga (RT), Jaelani (53 tahun) warga masyarakat, Nurul lailatul Badriyah (20 tahun) merupakan peserta festival yang menjadi "mayoret drumblek".

\section{PEMBAHASAN}

\section{Profil Desa Jatirejo Kec. Suruh, Kab.Semarang}

Desa Jatirejo merupakan sebuah Desa yang terletak di Kecamatan Suruh, Kabupaten Semarang, Jawa Tengah, Indonesia. Kecamatan Suruh sendiri terdiri dari 17 Desa dengan kepadatan 944 jiwa per-kilometer persegi dengan luas 64,02 kilometer persegi. Dari Ibu Kota Kabupaten Semarang yakni Kota Ungaran, Desa Jatirejo berjarak 33 kilometer melalui arah tenggara setelah Kota Salatiga, dan dari kota Surakarta berjarak sekitar 40 kilometer kearah barat daya jalur ke arah Kota Semarang. ${ }^{11}$

Desa Jatirejo memiliki beberapa potensi unggulan yang berkontribusi terhadap peningkatan kesejahteraan masyarakat, diantaranya adalah pertanian. Dalam bidang pertanian ini mampu meningkatkan pendapatan penduduk, karena di Desa Jatirejo memiliki area lahan persawahan yang cukup luas dan subur, sehingga masyarakat dapat memanfaatkan lahan tersebut untuk menanam padi, jagung, palawija, sayuran dan buah-buahan. Dari sektor pertanian tersebut masyarakat Desa Jatirejo dapat memperoleh hasil dari panen tanaman, sehingga mampu meningkatkan kesejahteraan masyarakat. ${ }^{12}$

Dalam bidang industri, sebagian masyarakat memproduksi berbagai macam makanan dalam home industry, yakni berupa industri kerupuk, tahu bakso, industri tempe dan terdapat beberapa masyarakat yang terampil dalam hal menjahit sehingga membuka usaha di rumah. Desa Jatirejo juga memiliki potensi unggulan di bidang wisata meliputi kuliner dan wisata religi yaitu: Sendang Pancuran Pitu Kali Klewon, Balai Panjang, Masjid Agung Jati (Sekarang Masjid Baiturrakhim), Makam Sunan Jati, Makam Petik Penawangan, Makam Kyai Jati, Makam Kun Razikin. Desa Jatirejo juga memiliki agenda rutin desa yakni, Sadranan, Suroan, Peringatan Hari Kemerdekaan Republik Indonesia Merti Desa dan Punggahan. ${ }^{13}$

\section{Sejarah Desa Jatirejo yang diyakini Masyarakat}

Menurut Fahrurrazi, ceritera tutur (folklore) yang berkembang dan dipercayai oleh masyarakat Desa Jatirejo berawal dari Abad ke-14 Masehi. Ketika itu Sunan Kalijaga berdakwah ke berbagai wilayah di Pulau Jawa. Sunan Kalijaga adalah salah seorang dari dewan Walisongo yang merupakan tokoh penyebar agama Islam di Pulau Jawa. Pada saat berdakwah Sunan

\footnotetext{
${ }^{11}$ Data Kelurahan Desa Jatirejo, Kecaman Suruh, Kab.Semarang Tahun 2019.

12 Wawancara dengan Anwar Hidayat (2019).

13 Ibid.
} 
Kalijaga didampingi tiga orang pengikutnya, yaitu: Syech Somadun, Nur Salim dan Petik Penawangan. Ketika sampai diwilayah tujuan mereka singgah sejenak. Pengikut Sunan Kalijaga diperintahkan untuk mencari informasi siapakah yang menguasai wilayah tersebut. Ketika para pengikut tersebut telah mendapatkan informasi bahwa yang berkuasa di wilayah itu bernama Demang Mangu Suropawiro, kemudian para pengikut tersebut menghadap kepada Sunan Kalijaga. Saat rombongan ingin bertamu ke rumah Demang Mangu Suropawiro, mereka berniat dengan jalan dakwah ingin mensyiarkan Ajaran Agama Islam. Sesampainya disana mereka dijamu dengan baik oleh Demang Mangu Suroparwiro. Sunan Kalijaga beserta pengikutnya menjelaskan tujuan dan maksud kedatangannya. Singkat cerita, Demang Mangu Suropawiro tertarik dengan ajaran Agama Islam dan kemudian mendirikan masjid sebagai sarana tempat ibadah. Setelah Demang Mangu Suropawiro memeluk Agama Islam kemudian berganti nama menjadi Ihsanul Ibrahim. ${ }^{14}$

Lebih lanjut Fahrurrozi mengatakan, Rencana pembangunan masjid berlanjut pada penentuaan tempat. Demang Mangu Suroprawiro bermusyawarah dengan Sunan Kalijaga. Disepakatilah wilayah timur desa sebagai rencana tempat pendirian masjid. Pada saat itu Sunan Kalijaga memukul batu yang ada di tempat tersebut maka mengalirlah mata air tujuh pancuran yang rencananya untuk tempat wudhu nantinya. Sekarang tempat tersebut sering disebut “Sendang Kali Klewon”. Setelah masjid tersebut berdiri dan Agama Islam berkembang, wilayah tersebut menjadi ramai. Lalu Sunan Kalijaga melanjutkan perjalanan menuju Demak. Wilayah tersebut diberi nama oleh Sunan Kalijaga dengan sebutan "Jatirejo", karena berasal (cikal bakal) dari daerah yang banyak pohon jati. Setekah di bangun menjadi masjid dan menjadikan wilayah tersebut "Rejo" atau dalam Bahasa Indonesia dapat diartikan "ramai". Demang Ihsanul Ibrahim diperintahkan untuk melanjutkan memimpin di wilayah tersebut dan diberi gelar "Sunan Jati". Sedangkan ke-tiga pengikutnya diperintahkan oleh Sunan Kalijaga untuk membantu Sunan Jati untuk bersyiar dan mengajarkan agama di wilayah tersebut. ${ }^{15}$

Selanjutnya pegikut Sunan Kalijaga yang bernama Syech Somadun diberi gelar "Kyai Jati" dikarenakan ilmu agamanya dianggap cukup oleh Sunan Kalijaga. Petik Penawangan diperintahkan oleh sunan kalijaga untuk mengumandangkan adzan setiap tiba waktu sholat. Sedangkan Nur Salim diberi gelar "Kun Razikin" oleh Sunan Kalijaga. Petilasan (artefak sejarah) tersebut sampai sekarang masih tetap dijaga kelestariannya oleh masyarakat dan pemerintah Desa Jatirejo. ${ }^{16}$

\footnotetext{
14 Wawancara dengan Fahrurrozi (2019).

15 Ibid

16 Wawancara dengan Fahrurrozi, lihat juga dalam https://website-desa-jatirejo-web.app/
} 


\section{Sejarah Masjid Agung Jati (Masjid Baiturrakhim)}

Masjid Agung Jati dipercaya oleh masyarakat Desa Jati didirikan oleh Sunan Kalijaga. Fahurrazi mengatakan bahwa dahulu gurunya yang bernama Hafik Amin (seorang kiai dan sesepuh desa) mengatakan bahwa Masjid Agung Jati di dirikan Sunan Kalijaga sekitar tahun 1450 M. "saat hendak membangun masjid, Sunan Kalijaga mengajak beberapa tokoh masyarakat berdiskusi di Balai Panjang". Di Balai yang tak jauh dari lokasi masjid, Sunan Jati (pendiri Desa Jatirejo) juga terlibat dalam perbincangan pembangunan masjid, yang dipercaya dibangun pada hari kamis. Lalu, pada keesokan harinya, Jumat Legi, diadakanlah syukuran dibalai panjang. ${ }^{17}$ Syukuran inilah yang kemudian diperingati oleh warga setempat pada setiap Jumat Legi untuk meminta berkah hingga sekarang. "dulu setiap Jumat Legi di lokasi Balai Panjang banyak orang yang berjualan makanan, jenang, kembang, maupun mereka yang menyebar uang. Bahkan ditempat itu juga digelar seni Reog". ${ }^{18}$

Diceritakan, dalam masjid ada beberapa kejadian unik yang terkadang sulit diterima akal sehat. Setiap menjelang waktu sholat Asar, ada yang bermain-main dengan pukulan kentongan diserambi masjid, tetapi wujudnya tidak terlihat. "pernah ada sebatang kayu masjid yang dicuri saat dilakukan rehab. Tetapi kayu tersebut kembali lagi ketempatnya." Kata Hafik dalam perkembangannya, masjid tersebut sudah mengalami beberapa kali perbaikan. Anwar Hidayat mengatakan bahwa yang masih asli dari peninggalan Sunan Kalijaga adalah tongkat khotbah dan salah satu tiang yang sekarang disimpan diatap masjid. ${ }^{19}$

\section{Pelaksanaan Tradisi Suroan di Desa Jatirejo Suruh, Kab. Semarang}

Proses pelaksanaan tradisi Suroan ini dilakukan melalui beberapa tahapan atau tata cara yaitu tahap persiapan, pelaksanaan dan penutup. Kegiatan persiapan yang dilakukan masyarakat diawali dengan adanya penentuan waktu dan tempat pelaksanaan acara Suroan, kemudian musyawarah antar warga dalam pembentukan kepanitian, masalah dana yang diperlukan dan perlengkapan yang diperlukan dalam Suroan. "Dananya untuk kegiatan Suroan untuk tahun kemarin iuran dari kas pemerintah desa, tapi yang tahun sebelumnya dari masyarakat ditambah, tapi kemungkinan besar untuk tahun selanjutnya akan dibiayai dari desa."20

Hasil observasi peneliti, pelaksanaan tradisi Suroan ini dimulai dengan pawai ta'aruf. Para peserta berkumpul tepat pukul 08.00 WIB di Dusun Dukuh. Ratusan warga desa mengikuti pawai ta'aruf (karnaval) yang dilaksanakan dalam rangkaian acara memperingati Tahun Baru

\footnotetext{
${ }^{17}$ Fahurrozi, op.cit.

${ }^{18}$ Wawancara dengan Anwar Hidayat.

${ }^{19}$ Ibid.

${ }^{20}$ Ibid.
} 
Islam 1 Muharram dari enam dusun di Desa Jatirejo ikut berpartisipasi dalam kegiatan tradisi Suroan tersebut. Pawai ta'aruf tersebut berlangsung meriah.para peserta karnaval diberangkatkan pukul 08.00 WIB. Mulai dari Dusun Dukuh, Gedhongan, lalu Dusun Krajan, melewati Dusun Klewonan, lalu Dusun Gruneng hingga sampai Dusun tepatnya di Bale Panjang.

Peserta pawai ta'aruf berjalan kaki menempuh rute sepanjang satu kilometer, mulai dari Dusun Dukuh hingga Dusun. Iring-iringan karnaval tersebut diawali rombongan pembawa panjipanji bertuliskan ayat Al-Qur'an yang mengenakan pakaian ala Walisongo. Di belakangnya, diikuti berbagai kesenian, berbagai replika Kabah, masjid dan replika Al-Qur'an. Selain itu, juga ada gunungan yang berisi beranekaragam hasil pertanian seperti tumbengan, sayur dan buahbuahan. Salah satu kesenian yang paling mendapatkan perhatian dan menarik adalah Tari Kuntulan (angguk). Sebab, kesenian ini terbilang langka dan hampir punah. Para penarinya juga kebanyakan adalah para orang tua. Mereka memakai pakaian putih berumbai warna-warni, memakai peci dan kacamata hitam serta membawa kipas ditangannya. Kesenian Tari Kuntulan atau rodad turut serta memeriahkan kegiatan pawai ta'aruf menyambut tahun baru Hijriyah.

Diiringi rebana dan lantunan syair-syair Jawa serta shalawat, mereka menari menyesuaikan ritmis dan secara dinamis. kegiatan ini selain bertujuan mempererat silaturahim antar-warga, juga bertujuan mengingatkan umat muslim agar memperbaharui lembaran hidup dengan tingkat keimanan dan ketakwaan yang lebih baik, tidak hanya syiar Islam, pawai ta'aruf ini juga mengusung pesan kepedulian terhadap lingkungan dan sosial. ${ }^{21}$

Pada pawai ta'aruf ini salah satunya ditampilkan oleh berbagai grup Drumblek yang salah satunya adalah grup Drumblek Laskar balai panjang, Drumblek yakni aneka tetabuhan dari bahan-bahan bekas seperti tong bekas, blek, kaleng, bambu, hingga kentongan. Dengan koreografi yang cantik, berbagai barang bekas tersebut ternyata bisa menghasilkan musik yang rampak dan dinamis. Selain musik, pesan mencintai lingkungan juga di tampilkan oleh sejumlah peserta yang memakai kostum dari koran bekas. Peserta pawai ta'aruf menyambut tahun baru Hijriyah di desa Jatirejo, Kecamatan Suruh, Kabupaten Semarang, melewati persawahan, Salah satunya diperagakan oleh Nurul Lailatul Badriyah.

Menurut Badriyah, untuk membuat satu kostumnya dibutuhkan sekitar 200 hingga 300 lembar lebih koran bekas dengan lama pembuatan memakan waktu hingga dua pekan. Dengan kostum koran tersebut, Badriyah ingin mengajak generasi muda lebih peduli pada kelestarian lingkungan. dilanjutkan di Petilasan Sunan Kalijaga Setelah menggelar karnaval budaya dengan menampilkan berbagai seni budaya masyarakat setempat. ${ }^{22}$

\footnotetext{
${ }^{21}$ Wawancara dengan Jaelani

22 Wawancara dengan Nurul Lailatul Badriyah
} 
Peringatan tahun baru Islam 1 Muharram di Desa Jatirejo masih berlanjut pada malam hari. Warga menggelar pengajian akbar dan haul, susunan acaranya yang meliputi: pembukaan, istighosah, yasinan, tawassul manaqib, manaqib, tahlil dan zikir, pembacaan ayat-ayat suci AlQur'an dan sholawat Nabi Sambutan-sambutan, istirahat, bersama hidangan yang selalu wajib ada yaitu "ayam ingkung" yang melambangkan pengorbanan yang tulus dan ucapan terimakasih baik kepada Allah maupun leluhur yang telah memberikan keselamatan dan perlindungan. Hal ini mengandung pesan agar manusia harus tahu terimakasih kepada siapa saja yang telah berbuat baik serta harus bersyukur kepada Allah atas nikmat yang telah diberikan-Nya.

Fahrurrazi mengatakan bahwa :

"Sego tumpeng iku disuguhake seko sego seng digawe krucut, coro nggawene iku sego didang lan dibentuk nganggo cetakan lan ditoto karo maneko warno lawuh, koyo dene, dNog pitik, ndog gemak, tahu, tempe, gereh asin, ayam goreng, perkedel kentang, sambel klopo, mie jagung, lan klubanan, lan tumpeng iku mau di biasi nganggo maneko warno sayuran koyo dene tomat, timun, lombok, slada,wortel den dibentuk maneko warno tumpeng disuguhake nganggo tampah seng kagawe soko anyaman pring."

Dalam tradisi Suroan masyarakat Jatirejo, Nasi Tumpeng disajikan dengan nasi yang dibentuk kerucut, pembuatannya dengan cara nasi dikukus dan dibentuk dengan cetakan dan di tata dengan berbagai macam lauk pauk, seperti telur( sebagai lambang dari wiji aji atau benih terjadinya manusia), tahu, tempe, ikan asin, ayam goreng, perkedel kentang, Sambal kelapa, mie jagung,dan urap, serta tumpeng dihias dengan berbagai macam sayuran, seperti bayam (sebagai simbol kehidupan manusia agar sejahtera dan tentram), kangkung (sebagai simbol manusia makhluk linakung atau tingkat tinggi), tomat (sebagai wujud perbuatan yang benar), kecambah (simbol manusia yang akan tumbuh) timun, lombok tropong atau cabai merah (sebagai simbol menegakkan kebenaran tuhan atau keberanian), kacang panjang (manusia supaya berfikir panjang) slada, wortel yang dibentuk dengan bervariasi. Tumpeng disajikan dalam nampan besar, berbentuk bulat, terbuat dari anyaman bambu).

Tumpeng yang bentuknya segi tiga melambangkan gunung, yang erat hubungannya dengan sesuatu yang bersifat spiritual. Bentuk segitiga juga merupakan hubungan antar manusia, alam, dan Sang Pencipta, jumlah lauk yang diletakkan di sekeliling tumpeng tersebut juga memiliki arti tersendiri, Angka tujuh dalam bahasa Jawa disebut dengan istilah pitu, atau pitulungan yang berarti adalah pertolongan, tujuh jenis lauk yang dihidangkan bersama tumpeng merupakan simbol do'a dan memohon pertolongan kepada Sang Pencipta agar diberi kelancaran 
dalam melaksanakan segala sesuatu dan susunan acara terakhir yaitu Mauidhoh hasanah dan Do'a. ${ }^{23}$

Haul ini bertujuan untuk peringatan hari wafatnya Sunan Jati, yakni tokoh penyebar agama Islam di desa tersebut yang konon hidup di era Wali Songo. Kegiatan Haul Sunan Jati bertempat di Balai Panjang di kompleks pemakaman sesepuh desa Jatirejo, Balai Panjang adalah sebuah gubuk jati yang diyakini oleh warga pernah menjadi tempat musyawarah untuk membangun masjid Baiturrahim Jatirejo, antara Sunan Kalijaga dengan Sunan Jati, syekh petik penawangan, syekh kurozikin, syekh somadun dan beberapa pengikutnya. Balai panjang ini setiap Jumat Legi pagi banyak di datangi warga luar desa untuk berdoa. Selain Balai Panjang, petilasan Sunan Kalijaga dan Sunan Jati yang masih bisa ditemui di Desa Jatirejo adalah Masjid Jatirejo, Wajan Raksasa, tombak peninggalan Sunan Kalijaga. Ada juga makam Khotib Penawangan, yakni seorang utusan kerajaan Demak yang ditugasi mencari keberadaan Sunan Kalijaga di Desa Jatirejo. Wajan raksasa dan tombak disimpan di masjid. Kalau tombaknya masih dipakai oleh khatib di mimbar setiap pelaksanaan sholat jumat. Kegiatan pawai ta'aruf dan Haul Sunan Jati di desa Jatirejo merupakan salah satu potret budaya masyarakat di Jawa Tengah dalam rangka menyambut Tahun Baru Hijriah.

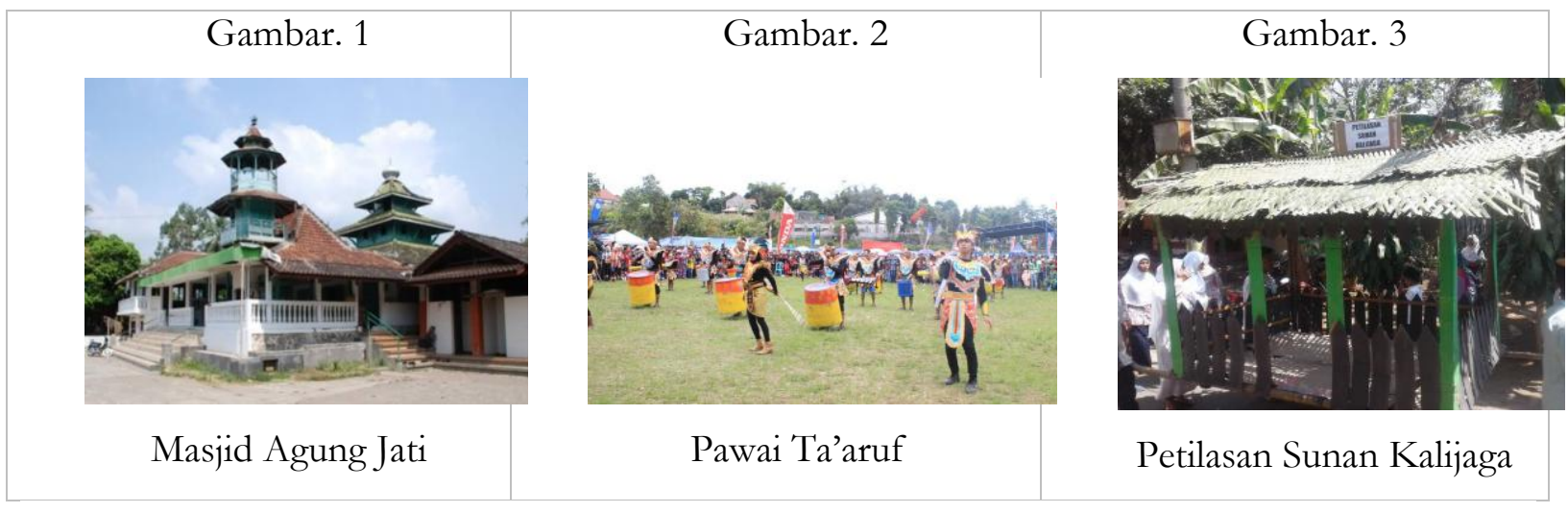

\section{Makna Pelaksanaan Tradisi Suroan di Desa Jatirejo}

Tidak semata-mata kegiatan budaya, banyak pesan yang ingin disampaikan melalui kegiatan Suroan yang salah satunya pawai ta'aruf menyambut tahun baru ini. Selain bermakna sebagai peninggalan leluhur dan sejarah, kegiatan ini juga membawa pesan agar warga membuat perubahan kearah yang lebih baik, seperti menjaga alam dan kelestarian lingkungan dan memperoleh keselamatan. Sesuatu yang sejalan dengan spirit Hijriah, yakni berhijrah menuju arah

${ }^{23}$ Febi Anindya Kirana, "Sejarah dan Filosofi Ayam Ingkung", di Akses dari https://www.fimela.com/lifestyle-relationship/read/3870155/sejarah-dan-filosofi-ayam-ingkung-lauk-utamatumpeng-dalam-adat-jawa, Pada Tanggal 13 September 2019 Pukul 13.00. 
yang lebih baik. Dan perlu diingat satu suro atau trasidi Suroan ini perlu dipertahankan karena bermuatan tradisi lokal, yang mengandung dimensi ekonomi maupun sosial yang bercorak spiritualitas. Tradisi suroa ini juga menjadi bagian dari transformasi nilai-nilai budaya lokal.

\section{Implikasi Suroan dalam Perspektif ekonomi dan keagamaan pada masyarakat Desa Jatirejo, Kecamatan Suruh}

Implikasi Suroan dalam perspektif ekonomi yang berkaitan dengan tradisi Suroan tapak tilas walisongo sendiri yaitu dalam perspektif ekonomi seluruh masyarakat turut berperan aktif atau berpartisipasi dalam memeriahkan acara Suroan (Tahun Baru islam) walaupun dari kalangan ekonomi yang berbeda. Dan dilihat dari perspektif keagamaan yaitu akan tumbuh rasa toleransi dan saling berbagi tanpa memandang dari latar belakang yang berbeda.

\section{Tradisi Suroan Dalam Pandangan Islam}

Dalam Islam, manusia dituntut bukan hanya untuk beriman saja dan rukun-rukun iman tidak untuk dijadikan semboyan dan slogan saja, akan tetapi Islam menuntut agar iman itu dibuktikan dalam perbuatan nyata. Sedang pembuktian dan realisasi daripada iman itu ialah mengerjakan semua petunjuk dan perintah Allah dan Rasul berdasar atas kemampuan maksimal, serta menjauhi segala larangannya, tanpa ditawartawar. Para ulama dalam meluruskan aqidah masyarakat tidak perlu melarang atau menghapus tradisi yang ada, bahkan dalam Syarah Muslim Imam Nawawi menyebut Muharram atau suro merupakan bulan yang paling utama untuk berpuasa, setelah bulan Ramadhan, keterangan dalam Hadist riwayat Muslim.

Menurut pandangan Islam Bulan Muharram atau Bulan Suro adalah bulan pelipat gandaan, artinya semua amal shalih yang dikerjakan seperti tradisi Suroan tapak tilas walisongo di Desa Jatirejo,suruh, Kab. Semarang ini akan berlipat-lipat ganda pahalanya. Oleh sebab itu, amaliah utama di bulan suro yang seharusnya dilakukan dibulan muharam atau suro adalah menjauh dari perbuatan zhalim dan mendekati pada perbuatan takwa (Surat al-Taubah[9]: 36) yang berbunyi:

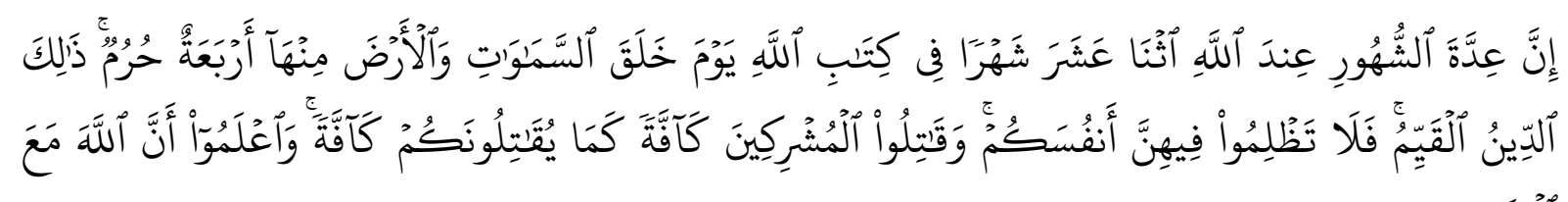

"Sesunggubnya bilangan bulan pada sisi Allah adalah dua belas bulan, dalam ketetapan Allah di waktu Dia menciptakan langit dan bumi, di antaranya empat bulan haram. Itulab (ketetapan) agama yang lurus, maka janganlah kamu menganiaya diri kamu dalam bulan yang empat itu, dan perangilah kaum musyrikin itu 
semuanya sebagaimana merekapun memerangi kamu semuanya, dan ketabuilah bahwasanya Allah beserta orang-orang yang bertakwa".

Dari ayat diatas maka dapat disimpulkan bahwa pelaksanaan tradisi Suroan dalam pandangan Islam sangat dianjurkan karena memiliki manfaat atau maslahat dibanding madharat (keburukan).

\section{Nilai-Nilai Pendidikan Dalam Tradisi Suroan}

Dalam setiap budaya atau tradisi tentunya ada beberapan nilai-nilai yang terkandung di dalam tradisi tersebut. Begitu juga pada tradisi peringatan bulan 1 Muharram atau bulan suro, dari pemaparan diatas banyak sekali nilai-nilai yang terkandung di dalam tradisi Suroan tapak tilas walisongo. Nilai-nilai yang terkandung antara lain:

Pertama, dalam tradisi Suroan tapak tilas Walisongo ini terdapat nilai pendidikan sejarah. Yaitu sejarah Masjid Baiturrakhim yang di bangun Sunan Kalijaga dan pengikutnya sekitar tahun 1450 M. Nilai-nilai sejarah ini bisa dilihat dari cerita perjuangan Sunan Kalijaga dalam dakwah Islamnya. Selain itu bisa dilihat juga dari peninggalan-peninggalannya yang berupa petilasan(Balai Panjang), Sendang Pancuran Pitu Kali Klewon, Masjid Agung Jati (Sekarang Masjid Baiturrakhim), Makam Sunan Jati, Makam Petik Penawangan, Makam Kyai Jati, Makam Kun Razikin yang ada di Desa Jatirejo, Suruh sebagai warisan budaya.

Kedua, dapat dilihat dalam acara pawai ta'aruf atau karnaval dan pengaiian akbar, nilai pendidikan nasehat kebaikan yang bisa diambil yaitu disisipkannya nilai-nilai pendidikan Islam, seperti halnya senantiasa bersyukur atas nikmat, senantiasa bersabar atas segala cobaan dan masih banyak lainnya.

Ketiga, masyarakat Desa Kuman Jatirejo, terdiri dari berbagai macam agama dan latar belakang yang beragam. Tradisi Suroan tapak tilas walisongo yang diselenggarakan di desa Desa Kuman Jatirejo ternyata dapat berperan untuk menggalang persatuan dan kesatuan warga setempat. Nilai persatuan dan kesatuan dapat dilihat pada waktu pelaksanaan upacara. Masyarakat melakukan gotong-royong dengan membersihkan fasilitas umum berupa sendang, jalan, makam dan lingkungan. Mereka melakukannya secara suka rela, hal tersebut dapat menjadi ciri khas warga masyarakat untuk dapat dilestarikan dan dipertahankan.

Keempat, keberlangsungan kearifan lokal yang tercermin dalam nilai-nilai yang berlaku dalam masyarakat di Desa Jatirejo, Suruh nilai-nilai itu menjadi pegangan yang biasanya akan menjadi bagian hidup tak terpisahkan yang dapat diamati melalui sikap dan perilaku mereka sehari-hari. Tradisi Suroan yang dilakukan masyarakat Desa Jatirejo mempunyai kearifan lokal tradisi yang dapat dilestarikan. 


\section{KESIMPULAN}

Berdasarkan analisis yang dilakukan terhadap penelitian ini, maka dapat saya simpulkan bahwa dalam tradisi Suroan yang terdapat di Desa Jatirejo, Kecamatan Suruh yang sampai saat ini masih dipertahankan, dilestarikan, dijaga, dan dilaksanakan setiap tahunnya. Dengan tata cara tahap persiapan, pelaksanaan, dan penutup. Dengan adanya kegiatan tradisi Suroan ini bertujuan agar warga senantiasa melakukan perubahan ke arah yang lebih baik, seperti lebih peduli terhadap lingkungan, menjaga alam dan melestarikan lingkungan sekitarnya terutama di daerah sendiri. Hal ini juga sejalan dengan spirit Hijriah, yakni berhijrah menuju arah yang lebih baik, lebih bermanfaat. Dalam lingkup wilayah Negara Kesatuan Republik Indonesia, kearifan lokal yang dimiliki oleh suatu daerah menunjukkan keberagaman jenis dan banyaknya tradisi yang terdapat di daerah Indonesia. Dari kearifan lokal yang dimiliki oleh suatu daerah tersebut dapat dijadikan sebagai modal dasar untuk memperkokoh jati diri/identitas suatu daerah tersebut dan sebagai asset kekayaan kebudayaan daerah tersebut yang dapat memberikan nilai tambah dari suatu daerah tersebut.

Kita harus bersikap bijaksana untuk mempertahankan nilai lama atau tradisi seperti tradisi Suronan yang baik dan menerima nilai baru yang lebih baik dan bermanfaat agar tetap sesuai dengan perkembangan zaman dan nilai ajaran Islam yang mulia. Selama tidak bertentangan dengan ajara Agama Islam, maka tradisi-tradisi seperti trasisi Suroan ini dapat dilaksanakan dan dikembangkan. Sebaliknya, jika bertentangan dengan ajaran Agama Islam maka tradisi-tradisi itu harus ditinggalkan dan tidak boleh dikembangkan.

\section{Saran}

Untuk generasi muslim umumnya dan muda khususnya dimasa muda agar dapat mengaplikasikan nilai-nilai budaya Islam dan Jawa, serta melestarikan budaya yang ada seiring dengan perkembangan kondisi dan situasi masyarakat, agar nilai-nilai budaya dan Islam yang terkandung semakin kuat dan berakar dalam kehidupan. Untuk pemerinta desa dan pemerintah kecamatan agar tetap bekerja sama dengan masyarakat setempat dan juga memperhatikan budaya-budaya yang tumbuh dalam masyarakat yag sudah turun temurun. Budaya dan tradisi yang tumbuh dimasyarakat tersebut merupakan ciri khas bagi masyarakat Desa Jatirejo yang memiliki keunikan tersendiri. 


\section{REFERENSI}

Syahri. 1985. Implementasi Agama Islam pada MasyarakatJawa. Jakarta: Depag. Halaman 2.

Al-Amri, L., \& Haramain, M. (2017). Akulturasi Islam Dalam Budaya Lokal. KURIOSITAS: Media Komunikasi Sosial dan Keagamaan, 10(2), 87-100.

Astuti, s. P., \& Pujiningsih, s. (2017). Eksplorasi anomali karakteristik motif batik batang dalam perspektif kaidah estetika seni rupa islam. Jurnal dimensi seni rupa dan desain, 13(2), 183208.

Baharun, H., Ulum, M. B., \& Azhari, A. N. (2018). Nilai-nilai Pendidikan Islam dalam Tradisi Ngejot: Konsep Edukasi dalam Membangun Keharmonisan dan Kerukunan Antarumat Beragama Berbasis Kearifan Lokal. FENOMENA, 10(1), 1-26.

Data Kependudukan dari Pemerintahan Desa Kuman Jatirejo, Kecamatan Suruh, Kab. Semarang, 2019.

Endraswara, Suwardi, Falsafah Hidup Jawa, Yogyakarta: Cakrawala, 2010

Ensiklopedi Islam, PT. Intermasa, Jakarta, 1990

Fatah, Munawir Abdul, Tradisi Orang-Orang NU (Yogyakarta: Pustaka Pesantren, 2007) hlm. 291

Halimuddin, Kembali Kepada Aqidah Islam, cet. I, Jakarta: Rineka Cipta, 1990.

Hanik, U. (1994). Unsur Keislaman Pada Tradisi Suroan Di Petilasan Sri Aji Jayabaya Desa Menang Kecamatan Pagu Kabupaten Daerah Tingkat Ii Kediri (Doctoral dissertation, UIN Sunan Ampel Surabaya).

Junaid, H. (2013). Kajian Kritis Akulturasi Islam dengan Budaya Lokal. Jurnal Diskursus Islam, 1(1), 56-73.

Kahmad, Dadang, Metode Penelitian Agama "Perspektif Ilmu Perbandingan Agama", Bandung: Pustaka Setia, 2000

Kholid, A. I. (2016). Wali Songo: eksistensi dan perannya dalam islamisasi dan implikasinya terbadap munculnya tradisi-tradisi di tanah jawa. Jurnal Tamaddun: Jurnal Sejarah dan Kebudayaan Islam, 1(1).

Luthfi, K. M. (2016). Islam Nusantara: Relasi Islam dan Budaya Lokal. SHAHIH: Journal of Islamicate Multidisciplinary, 1(1), 1-12.

Madjid, Nurcholis, Islam Agama Peradaban: Membangun Makna Dan Relevansi Doktrin Islam Dalam Sejarah, Cet II, Jakarta: Paramadina, 2000

Maryaeni, 2005. Metode Penelitian Kebudayaan. Jakarta : Budi Aksara. 
Nashir ibn Abdul Karim Al-'Aql, Prinsip-Prinsip Aqidah, Jakarta: Gema Insani Press, 1997

Purwadi, 2005. Upacara Tradisional Jawa Menggali Untaian Kearifan Lokal. Yogyakarta : Pustaka Pelajar.

Sholikhin, M. (2010). Misteri bulan Suro: perspektif Islam Jawa. Penerbit Narasi.

Sri Muryati, S. (2013). Pelestarian Budaya Nasional Melalui Kegiatan Tradisional. PAWIYATAN, 20(3).

Sutiyono, 2013. Poros Kebudayaan Jawa. Yogyakarta: Graha Ilmu. Halaman 1.

\section{Interview:}

Wawancara dengan Fahrurrazi Alwi (42 Tahun), sebagai tokoh agama Desa Jatirejo, pada tanggal 24 Oktober 2019, Jam 21.10 WIB

Wawancara dengan Jaelani(53 Tahun), sebagai Masyarakat Desa Jatirejo, pada tanggal 10 Oktober 2019,Pada Jam 15.24 WIB

Wawancara dengan Anwar Hidayat( 45 Tahun), sebagai Kepala Dusun, pada tanggal 09 November 2019, Pada Jam 10.59 WIB,

Wawancara dengan Rizal (36 Tahun), sebagai Ketua rukun tetangga (RT), pada tanggal 09 November 2019, Pada Jam 08.00 WIB

Wawancara kepada Nurul lailatul Badriyah(20 Tahun), sebagai peserta pawai ta'aruf, pada tanggal 09 November 2019, Pada Jam 16.00 WIB 